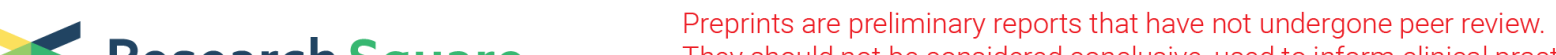 Research Square They should not be considered conclusive, used to inform clinical practice, or referenced by the media as validated information.
}

\section{Reference gene selection in multiple Passiflora edulis tissues and under cold stress for RT- qPCR analysis}

\section{Zhonghua Tu}

Nanjing Forestry University https://orcid.org/0000-0002-2313-8550

Hang Fan

Nanjing Forestry University

Anding Li

Institude of Mountain Resources, Guizhou Academy of Sciences

Na Ran

Nanjing Forestry University

Ke Ding

Nanjing Forestry University

Meng Xu ( $\nabla$ xum@njfu.edu.cn )

https://orcid.org/0000-0002-6573-9098

\section{Research article}

Keywords: P. edulis, reference genes, RT-qPCR, expression stability, data normalization

Posted Date: April 29th, 2020

DOI: https://doi.org/10.21203/rs.3.rs-25297/v1

License: (c) (i) This work is licensed under a Creative Commons Attribution 4.0 International License.

Read Full License 


\section{Abstract}

Background: Passiflora edulis is a tropical fruit with high edible and medicinal values that is widely cultivated in southern China. The development of new $P$. edulis variety with cold resistance and research on the mechanism of cold resistance are the basis for further promoting the cultivation of this species. In a previous study, our laboratory discovered a cold-resistant variety Pingtang 1 , which is used as a material for the study of cold resistance mechanism in $P$. edulis. However, functional genes of $P$. edulis have not been well studied, especially via relative quantitative analysis. In addition, research on reference genes in P. edulis has not been reported.

Results: We used three tools to test the expression stability of 10 candidate reference genes in multiple tissue samples and cold-treated samples of $P$. edulis. We found that Ts and EF1 showed the highest expression stability in all samples. Further analysis showed that HIS and EF1 were stably expressed in tissue samples, whereas $U B Q$ and $E F 1$ were stably expressed in cold-treated samples. Interestingly, EF1 was stably expressed in not only multiple tissue samples but also cold-treated samples. To validate the selected reference genes, we used the target gene ICE 1 and investigated its expression level in coldtreated leaves. Interestingly, the expression of ICE1 increased with increasing cold treatment times.

Conclusions: In this study, we successfully selected reference genes from among 10 candidates for $P$. edulis RT-qPCR data normalization. We selected Ts and EF1 as reference genes for normalization in all samples. HIS and EF1 were ideal for data normalization in tissue samples, whereas UBQ and EF1 were ideal for cold-treated samples. Our work substantially benefits the study of functional genes in $P$. edulis.

\section{Background}

Passiflora edulis (P. edulis), or passion fruit, is a perennial vine that belongs to the Passifloraceae family. $P$. edulis, which origined in South America, is now widely cultivated in southern China because of its high edible value, medicinal efficacy and ornamental properties; additionally, $P$. edulis is an important raw material in the juice and pulp industry [1-6]. Passion fruit, a tropical fruit, provides a variety of nutrients, such as carbohydrates, vitamins and minerals, which are essential for biological activities [5]. P. edulis was introduced in China at the beginning of the last century [2]. In recent years, researchers have studied the adaptability of $P$. edulis to cold environments, providing a theoretical basis for expanding the cultivation area of $P$. edulis in China $[1,2]$. Although the edible value and medicinal efficacy of $P$. edulis have increased, only a few studies on the functional genes of $P$. edulis have been reported, especially on gene expression patterns under cold conditions. Previously, our laboratory had discovered a cold resistant variety Pingtang 1 , which has been used as a material for research on cold resistance mechanisms in $P$. edulis. In the future, further research will be focused on the cold resistance mechanism and functional genes in $P$. edulis, that are associated with flavor, color, nutritional elements, medicinal compounds and environmental adaptability. However, before such studies can be performed, suitable internal control genes for reverse transcription quantitative polymerase chain reaction (RT-qPCR) data normalization in $P$. edulis must be selected. 
RT-qPCR, as a technology that has high throughput, high accuracy, and high sensitivity, is widely applied in functional gene expression pattern studies [7, 8]. Nonetheless, using RT-qPCR to investigate gene expression levels requires stably expressed reference genes for data normalization, and the expression stability of reference genes directly affects the accuracy of relative quantitative analyses [7, 9-12]. In theory, reference genes should have stable expression patterns in different samples and under different experimental conditions, yet no reference gene has satisfied these conditions simultaneously $[8,11,13-$ 16]. To our knowledge, a candidate reference gene may exhibit distinct expression patterns in different tissues within a species, and it may also exhibit various expression patterns under different conditions even in the same tissue $[15,17,18]$. For example, Actin 6 shows distinct expression levels under different types of abiotic stress in Pinus massoniana Lamb [18]. In Liriodendron chinense, Ubiquitin 1 exhibits various expression levels in multiple tissues [19]. Therefore, comprehensive evaluation and selection of appropriate internal control genes is a prerequisite for obtaining accurate and reliable relative quantitative results.

To date, many tools have been used to evaluate the expression stability of candidate reference genes. The most commonly used tools are geNorm, NormFinder and BestKeeper [20-22]. These three tools have been successfully used for the selection of reference genes in amaranth (Amaranthus tricolor), Setaria viridis, Carex rigescens, Lolium multiflorum, Euscaphis konishii Hayata, P. massoniana, Alopecurus aequalis Sobol, Carica papaya L., Olea europaea L., Cucurbita pepo, Brassica napus, L. chinense and Populus [18, 19, 23-33]. The use of multiple tools to select internal control genes for RT-qPCR data normalization has become a basic and indispensable process in the study of the expression patterns of functional genes. However, the studies on reference gene selection in $P$. edulis have not yet been performed, which has hindered the study of functional gene expression patterns in $P$. edulis.

In this work, we used 3 tools, namely, BestKeeper, geNorm, and NormFinder, to comprehensively evaluate the expression stability of $50 S$ (50S ribosomal protein), TS (threonine synthase), UBQ (ubiquitin), OTU (OTU domain-containing protein), $18 \mathrm{~S}$ (18S ribosomal RNA), $\mathrm{OmpH}$ (Outer membrane protein), EF1 (elongation factor 1 alpha), elF5A (eukaryotic translation initiation factor 5A), HIS (histone H3), and Liom (Theobroma cacao L-isoaspartate 0-methyltransferase mRNA) and then to select genes with high expression stability for application in RT-qPCR data normalization in $P$. edulis. To further understand the scope of the application of reference genes in P. edulis, we classified 60 samples into two subsets, namely, tissue samples and cold-treated samples. Moreover, we used ICE1 (inducer of C-repeat-binding factor (CBF) expression) as a target gene to validate the internal control genes that we selected. We investigated the expression level of ICE1 in leaves that were treated with cold stress for different lengths of time. This work will provide reliable internal control genes for the study of functional gene expression levels in $P$. edulis, especially under cold stress.

\section{Results}




\section{Amplification Efficiency Calculation and Primer Specificity Verification}

Using LinRegPCR 2014.x software, we calculated the mean amplification efficiency of all primers based on row data obtained by RT-qPCR, and the mean amplification efficiencies of the primers ranged from 1.762 (HIS) to 1.963 (18S) (Table 1) [34]. The primer specificity was validated by melting curve analysis. As shown in Fig. 1, each melting curve had only a single peak. This result indicated that the amplification was specific, and the RT-qPCR data could be used for further analysis. 
Table 1

Description of candidate reference genes.

\begin{tabular}{|c|c|c|c|c|}
\hline Name & Annotation & Primer sequence $\left(5^{\prime}-3^{\prime}\right)$ & $\begin{array}{l}\text { Amplicon } \\
\text { length } \\
\text { (bp) }\end{array}$ & $\begin{array}{l}\text { Mean } \\
\text { PCR } \\
\text { efficiency }\end{array}$ \\
\hline \multirow[t]{2}{*}{$50 S$} & $50 S$ ribosomal protein & F: GCGCATTCGGCGAAACTCAC & 126 & 1.830 \\
\hline & & R: ATCAGGGCCATGACCACCCA & & \\
\hline \multirow[t]{2}{*}{ Ts } & Threonine synthase & F: CAGTTGGTGCAGCCCATTGC & 93 & 1.861 \\
\hline & & R: GGCCGTAACCTCGCGAATGA & & \\
\hline \multirow[t]{2}{*}{$U B Q$} & Ubiquitin & F: TCAGTCACCTCCGGCCTTCT & 100 & 1.880 \\
\hline & & R: CGAGTGTGGTGCCGGAACTT & & \\
\hline \multirow[t]{2}{*}{ OTU } & $\begin{array}{l}\text { OTU domain-containing } \\
\text { protein }\end{array}$ & F: TCGTGCTCTGCTTCGGGTTT & 144 & 1.819 \\
\hline & & R: CACCACAGTTCCTCGGCGTA & & \\
\hline \multirow[t]{2}{*}{$\mathrm{OmpH}$} & Outer membrane protein & $\begin{array}{l}\text { F: } \\
\text { AGAGGCAAGATGACACCTCAGGA }\end{array}$ & 100 & 1.834 \\
\hline & & R: TTCGACCAGGCAACTTGCGA & & \\
\hline \multirow[t]{2}{*}{ Liom } & \multirow{2}{*}{$\begin{array}{l}\text { Theobroma cacao L- } \\
\text { isoaspartate O- } \\
\text { methyltransferase mRNA }\end{array}$} & F: TAAGGCAGCGACGGCATCAG & 127 & 1.829 \\
\hline & & R: TTTCAGCGAGCACGGTCAGG & & \\
\hline \multirow[t]{2}{*}{ EF1 } & Elongation factor 1 alpha & F: GGCTGAGCGTGAACGTGGTA & 146 & 1.827 \\
\hline & & R: CGGCACAATCAGCCTGGGAA & & \\
\hline \multirow[t]{2}{*}{$18 S$} & $18 \mathrm{~S}$ ribosomal RNA & F: TTAAGGCCAGGAGCGCATCG & 150 & 1.963 \\
\hline & & R: AGCCGCGGTAATTCCAGCTC & & \\
\hline \multirow[t]{2}{*}{ elF5A } & Eukaryotic translation & F: TGGGCCGATGTCCTTGAGAGA & 139 & 1.786 \\
\hline & & R: GGATGACTTGAGGCTCCCAACTG & & \\
\hline \multirow[t]{2}{*}{$H I S$} & Histone H3 & F: AGAGCCATGCAGTGTTGGCA & 92 & 1.762 \\
\hline & & R: CTTGGCGTGGATGGCACAGA & & \\
\hline
\end{tabular}

\section{Ct Values of Candidate Reference Genes}

We obtained cycle threshold $(\mathrm{Ct})$ values for the 10 candidate reference genes in 60 samples via RT-qPCR. A low $\mathrm{Ct}$ value indicates a high expression level, and a small difference between the maximum $\mathrm{Ct}$ value and the minimum $\mathrm{Ct}$ value indicates low variation in expression level. The mean $\mathrm{Ct}$ values of these genes ranged from $5.99(18 S)$ to $26.75(\mathrm{OmpH})($ Fig. 2). The results indicated that $18 \mathrm{~S}$ had the highest 
expression level among the samples and that $\mathrm{OmpH}$ had the lowest expression level. Moreover, $18 \mathrm{~S}$ showed the least variable expression levels among the 60 samples (maximum $\mathrm{Ct}$ value - minimum $\mathrm{Ct}$ value $=1.94 \mathrm{Ct}$ ), while $\mathrm{OmpH}$ showed the most variable expression levels (maximum Ct value - minimum $\mathrm{Ct}$ value $=12.07 \mathrm{Ct}$ ) (Fig. 2). Apparently, $18 \mathrm{~S}$ can be used as a reference gene, but this needs further analysis. In studies on rice (Oryza sativa) and Dimocarpus longan Lour, $18 \mathrm{~S}$ also showed small variable expression levels, but it cannot be used as reference gene [35, 36].

\section{Results of the geNorm Analysis}

The $M$ value was used to evaluate the expression stability of genes by geNorm software. Genes with relatively small $M$ values have high expression stabilities. An $M$ value greater than 1.5 indicates an unstable gene [20]. In all samples, Ts and EF1 had the most stable expression patterns (Fig. 3a). Among tissue samples, the best choices for normalization were Ts and HIS (Fig. 3b). For cold-treated samples, $U B Q$ and HIS showed the most stable expression patterns (Fig. 3c). OmpH and $18 S$ showed the least stable expression patterns under these conditions (Fig. 3a, b, c).

The pairwise variation $V_{n / n+1}$ was calculated to determine the minimum number of reference genes for accurate normalization [20]. If $\mathrm{V}_{\mathrm{n} / \mathrm{n}+1}$ values exceed 0.15 , an additional internal control gene must be included for normalization [20]. We found that $V_{2 / 3}$ was less than 0.15 in all samples, tissue samples, and cold stress-treated samples (Fig. 4). This suggested that the minimum number of reference genes for accurate normalization was two.

\section{Results of the NormFinder Analysis}

The stability values were calculated by NormFinder to evaluate gene expression stability. Low stability values indicate high expression stability [21]. We found that $T s$ had the most stable expression level in all samples (Fig. 5a). In tissue samples, HIS had the highest expression stability, followed by EF1 (Fig. 5b). Among cold-treated samples, $U B Q$ showed the most stable expression pattern, while $E F 1$ had the second most stable pattern (Fig. 5c). Notably, TS, HIS, and $U B Q$ were also recommended as internal control genes by geNorm software in all samples, tissue samples, and cold-treated samples, respectively (Fig. 3a, b, c).

However, there were some differences between the geNorm analysis and NormFinder analysis. For example, in all samples, EF1 ranked first in geNorm but fourth in NormFinder (Fig. 3a and Fig. 5a). In tissue samples and cold-treated samples, EF1 ranked second in NormFinder and ranked fourth and fifth in geNorm, respectively (Fig. 3b, c and Fig. 5b, c).

\section{Results of the BestKeeper Analysis}

In the BestKeeper algorithm, genes with a standard deviation (SD) value more than 1 are regarded as unacceptable [22]. In addition, $r^{2}$ ( $r$ represents the Pearson correlation coefficient) values close to 1 indicate a gene with an increasingly stable expression pattern [22]. In all samples, 50S, HIS, Liom and 
$\mathrm{OmpH}$ were unsuitable for data normalization (SD value $>1$ ), while Ts exhibited the most stable expression level followed by EF7 (Table 2). Similarly, 50S, Liom and OmpH were unsuitable for data normalization in tissue samples, while EF1 and HIS showed the highest expression stability in this case (Table 2). For the cold-treated samples, $\mathrm{OmpH}$ was unsuitable for normalization (SD value $>1$ ), while $U B Q$ showed the highest expression stability, followed by Ts (Table 2).

We found that Ts was suggested as a reference gene by BestKeeper, NormFinder and geNorm in all samples (Fig. 3a, Fig. 5a, Table 2), and UBQ had the highest expression stability calculated by the three tools in cold-treated samples (Fig. 3c, Fig. 5c, Table 2). Among tissue samples, the expression stability of HIS ranked first in geNorm and NormFinder, and second in BestKeeper (Fig. 3b, Fig. 5b, Table 2). Notably, $\mathrm{OmpH}$ showed unstable expression levels in all samples, tissue samples and cold-treated samples (Fig. 3, Fig. 5, Table 2). However, the rankings of these 10 genes were slightly different among the three algorithms. For example, in tissue samples, the Ts gene ranked first in geNorm, third in NormFinder and fifth in BestKeeper (Fig. 3b, Fig. 5b, Table 2). Among cold-treated samples, the EF1 gene ranked fifth in geNorm, second in NormFinder and third in BestKeeper (Fig. 3c, Fig. 5c, Table 2). EF1 also ranked differently in the analysis results of the three tools among all samples (Fig. 3a, Fig. 5a, Table 2). The reason for this phenomenon is that these tools use different algorithms to evaluate the expression stability of genes.

Table 2

Results of the BestKeeper tool analysis.

\begin{tabular}{|c|c|c|c|c|c|c|c|c|c|}
\hline \multirow[t]{2}{*}{ Rank } & \multicolumn{3}{|l|}{ All samples } & \multicolumn{3}{|c|}{ Cold-treated samples } & \multicolumn{3}{|c|}{ Tissue samples } \\
\hline & Gene name & $S D$ & $r^{2}$ & Gene name & SD & $r^{2}$ & Gene name & SD & $r^{2}$ \\
\hline 1 & Ts & 0.84 & 0.85 & $U B Q$ & 0.48 & 0.78 & EF1 & 0.70 & 0.74 \\
\hline 2 & EF1 & 0.79 & 0.83 & Ts & 0.48 & 0.68 & HIS & 0.59 & 0.70 \\
\hline 3 & elF5A & 0.76 & 0.75 & EF1 & 0.55 & 0.66 & OTU & 0.89 & 0.69 \\
\hline 4 & OTU & 0.91 & 0.74 & Liom & 0.58 & 0.62 & elF5A & 0.99 & 0.68 \\
\hline 5 & $U B Q$ & 0.50 & 0.62 & $50 S$ & 0.59 & 0.60 & Ts & 0.72 & 0.65 \\
\hline 6 & $18 S$ & 0.28 & 0.62 & HIS & 0.68 & 0.55 & $U B Q$ & 0.42 & 0.55 \\
\hline 7 & $50 S$ & 1.33 & 0.87 & $18 S$ & 0.22 & 0.48 & $18 S$ & 0.24 & 0.49 \\
\hline 8 & HIS & 1.27 & 0.86 & elF5A & 0.40 & 0.46 & $50 S$ & 1.11 & 0.74 \\
\hline 9 & Liom & 1.33 & 0.86 & OTU & 0.56 & 0.38 & Liom & 1.14 & 0.72 \\
\hline 10 & $\mathrm{OmpH}$ & 2.21 & 0.77 & $\mathrm{OmpH}$ & 1.12 & 0.44 & $\mathrm{OmpH}$ & 2.90 & 0.69 \\
\hline
\end{tabular}


Table 3

Top five genes ranked by the three tools.

\begin{tabular}{|c|c|c|c|c|c|c|}
\hline \multirow[t]{2}{*}{ Tools } & \multicolumn{2}{|c|}{ All samples } & \multicolumn{2}{|c|}{ Tissue samples } & \multicolumn{2}{|c|}{ Cold-treated samples } \\
\hline & Rank & Gene name & Rank & Gene name & Rank & Gene name \\
\hline \multirow[t]{5}{*}{ geNorm } & 1 & Ts & 1 & Ts & 1 & $U B Q$ \\
\hline & 1 & EF1 & 1 & HIS & 1 & HIS \\
\hline & 3 & elF5A & 3 & $U B Q$ & 3 & OTU \\
\hline & 4 & OTU & 4 & EF1 & 4 & elF5A \\
\hline & 5 & HIS & 5 & OTU & 5 & EF1 \\
\hline \multirow[t]{5}{*}{ NormFinder } & 1 & Ts & 1 & HIS & 1 & $U B Q$ \\
\hline & 2 & OUT & 2 & EF1 & 2 & EF1 \\
\hline & 3 & elF5A & 3 & Ts & 3 & elF5A \\
\hline & 4 & EF1 & 4 & $U B Q$ & 4 & Liom \\
\hline & 5 & $50 S$ & 5 & OTU & 5 & OTU \\
\hline \multirow[t]{5}{*}{ BestKeeper } & 1 & Ts & 1 & EF1 & 1 & $U B Q$ \\
\hline & 2 & EF1 & 2 & HIS & 2 & Ts \\
\hline & 3 & elF5A & 3 & OTU & 3 & EF1 \\
\hline & 4 & OTU & 4 & elF5A & 4 & Liom \\
\hline & 5 & $U B Q$ & 5 & Ts & 5 & $50 S$ \\
\hline
\end{tabular}

\section{Reference Gene Determination}

Through the analyses of the three tools, two reference genes were found to be sufficient for accurate normalization in all samples, tissue samples and cold-treated samples (Fig. 4). Our results suggested that Ts and EF1 was the best combination for accurate normalization in all samples (Table 3). Moreover, HIS and EF1 were selected as reference genes in tissue samples (Table 3). Under cold stress, UBQ and EF1 were the best choices for accurate normalization (Table 3). Notably, among all samples, tissue samples and cold-treated samples, $\mathrm{OmpH}$ was always the least stably expressed gene, indicating that $\mathrm{OmpH}$ was unsuitable for RT-qPCR data normalization under these conditions (Fig. 3, Fig. 5, Table 2). Although the $18 S$ gene possessed least variable expression levels among the 60 samples (Fig. 2), geNorm and NormFinder analysis showed that $18 \mathrm{~S}$ had an unstable expression pattern (Fig. 3 and Fig. 5). We suggest that $18 S$ should not be used as a reference gene.

\section{Verification of Reference Genes}


To verify the reference genes Ts and EF1, we used ICE1 as a target gene and Ts and EF1 as internal control genes. ICE1 is a transcription factor that can regulate the expression of the downstream $C B F$ gene, thereby improving plant resistance to cold stress [37]. In the leaves of $P$. edulis, when we used Ts and EF1 as internal control genes, we found that the expression level of ICE1 improved with increasing cold treatment times (Fig. 6). This phenomenon was consistent with the findings of a previous study [37]. This suggests that ICE1 may increase the stability of $P$. edulis to cold stress.

\section{Discussion}

Reference genes are used for RT-qPCR data normalization. The expression stability of reference genes can directly influence the accuracy of RT-qPCR, and reference genes should sustain stable expression levels in various tissues and under distinct experimental conditions [7, 38]. To our knowledge, the expression levels of genes vary with changes in tissue, species and experimental conditions [11]. Therefore, a gene must be strictly screened before being used as a reference gene to ensure the accuracy of RT-qPCR analysis. In addition, functional genes of $P$. edulis have not been well studied, especially by relative quantitative analysis of functional genes, and research on reference genes in $P$. edulis has not been reported. [1, 2]. To enhance the reliability of functional gene expression research, we systematically selected reliable internal control genes for RT-qPCR data normalization in multiple tissue samples and cold-treated samples of $P$. edulis.

In this work, we selected 10 candidate reference genes, namely, 50S, Ts, UBQ, OUT, OmpH, EF1, 18S, eIF5A, HIS, and Liom, and we used RT-qPCR to obtain their Ct values in 60 samples. Through analysis based on Ct values, we found that $18 \mathrm{~S}$ had the highest expression level $(5.99 \mathrm{Ct})$ and the smallest expression variation $(1.94 \mathrm{Ct})$, while $\mathrm{OmpH}$ had the lowest expression level $(26.75 \mathrm{Ct})$ and the largest expression variation (12.07 Ct) (Fig. 2). However, we could not use $18 \mathrm{~S}$ a reference gene due to its low expression variation. According to previous studies, genes with low expression variation may not be suitable for data normalization, and reference genes must be evaluated comprehensively by using different tools $[39,40]$. For example, research conducted on rice and $D$. longan showed that $18 S$ cannot be used as an internal control gene [35,36]. In particular, in research conducted on Bixa orellana, although $18 S$ had the highest expression level and the smallest expression variation, further analysis results showed that $18 \mathrm{~S}$ was the most unstable gene in multiple tissues and at different seed development stages [8]. This result indicated that $\mathrm{Ct}$ values of candidate reference genes were not enough to determine the expression stability.

Through further analysis by geNorm, NormFinder, and BestKeeper, Ts and EF1 were found to be ideal for data normalization in all samples (Table 3). The protein encoded by Ts can catalyze the last step of threonine biosynthesis, and there are many reports about its structure, expression and function [41, 42]. However, there are few reports about Ts as an internal control gene. EF1 is stably expressed in not only $P$. edulis, but also other plants. For example, EF1 was used as an internal control gene in Ilex paraguariensis leaves and potato (Solanum tuberosum L.) under abiotic stress $[43,44]$. To our knowledge, the expression level of reference genes may change with changes in species, experimental conditions, and tissue types. 
For example, although EF1 was suitable for data normalization in $P$. edulis, potato under abiotic stress, drought-treated leaves of I. paraguariensis, and Betula luminifera, this gene was unsuitable for data normalization in Camellia sinensis under metal stress and in leaves of Camellia sinensis [38, 43-46]. Overall, Ts and EF1 have the highest expression stability, but if we classify all samples into different subsets, there may be other genes in each subset with higher expression stability than Ts and EF1.

To determine whether there were other genes that had higher expression stability than Ts and EFT in different sample subsets, we classified the 60 samples into two subsets, namely, tissue samples and cold-treated samples. In previous studies on reference gene selection in different species, we found that the expression patterns of candidate reference genes may differ between nonstress and abiotic stress conditions $[23,47]$. Under nonstress conditions, HIS and EF1 was the best combination for data normalization in tissue samples (Table 3). In L. multiflorum, HIS also showed a stable expression pattern under acidic aluminum stress and heavy metal stress, while it could not be selected as an internal control gene in Populus tomentosa due to its poor expression stability $[26,48]$. Under cold stress conditions, UBQ and EF1 were sufficient for data normalization in P. edulis (Table 3). UBQ was also used as a reference gene in cotyledons of Cunninghamia lanceolata [11]. However, this gene was unsuitable for data normalization in Bursaphelenchus mucronatus and lettuce (Lactuca sativa) $[49,50]$. Compared with $T s$, HIS had higher expression stability in tissue samples and $U B Q$ had higher expression stability in coldtreated samples. This finding indicates that $H I S$ and $U B Q$ can be used as internal control genes in only specific samples and experimental conditions. Moreover, $18 S$ and Liom were unstably expressed in this study, and $18 S$ also showed unstable expression patterns in amaranth, B. orellana and Stellera chamaejasme (Fig. 3, Fig. 5, Table 2) [8, 23, 51]. However, 185 could be used for data normalization in Bursaphelenchus mucronatus and C. sinensis under metal stress $[45,49]$.

As a nutritious tropical fruit, $P$. edulis is widely cultivated in southern China [2]. However, cold resistance has been an important factor limiting the expansion of the $P$. edulis cultivation area. Our laboratory discovered a cold-resistant variety, Pingtang 1 , which is used as sample material for the study of cold resistance mechanisms. Our previous research has shown that the ICE1-CBF-COR pathway plays a crucial role in the cold tolerance of $P$. edulis [2]. ICE1 is a transcription factor that can regulate the expression of the downstream $C B F$ gene, thereby improving plant resistance to cold stress [37]. To validate the reference genes that we selected, we used ICE1 as a target gene and TS and EF1 as internal control genes, to investigate the expression level of ICE1 in cold-treated leaves of $P$. edulis. We found that the expression level of ICE1 increased with increasing cold-treatment times (Fig. 6). In previous studies, increased expression of ICE1 enhanced plant resistance to cold stress [37, 52]. Therefore, the increase in ICE1 expression may enhance the adaptability of $P$. edulis to cold stress.

Our work will facilitate the study of functional gene expression levels in $P$. edulis. We selected stable and reliable internal control genes and applied these genes in RT-qPCR data normalization in different tissue samples and under cold stress conditions in P. edulis.

\section{Conclusions}


In this study, we successfully selected reference genes from among 10 candidates for $P$. edulis RT-qPCR data normalization. In all samples, Ts and EF1 were the best reference genes for data normalization; HIS and $E F 1$ were ideal for tissue samples, and $U B Q$ and $E F 1$ were the best internal control genes for coldtreated samples. In conclusion, this work provides reliable and effective reference genes for gene expression level analysis in $P$. edulis.

\section{Methods}

\section{Plant Materials and Stress Treatment}

Plant materials were sampled from adult $P$. edulis "Pingtang 1" (a new P. edulis variety with cold resistance was developed by Institute of Mountain Resources in Pingtang County, Guizhou Province, and the voucher specimen was deposited in the Herbarium of Guizhou Academy of Sciences, voucher no. A.L2008001) individuals planted in Pingtang County, Guizhou Province ( $\left.25^{\circ} 44^{\prime} 77^{\prime \prime} \mathrm{N}, 106^{\circ} 48^{\prime} 45^{\prime \prime} \mathrm{E}\right)$. "Pingtang 1" survived the 2008 Snow Disaster in China (average temperature below $-2{ }^{\circ} \mathrm{C}$ ), and our laboratory completed its transcriptome sequencing in 2017 [2]. A total of 60 samples were classified into two subsets, tissue samples and cold stress-treated samples. Tissue samples included stems, leaves (mature leaves and immature leaves), fruits (young, adult, and old), flowers (buds and blooming flowers) and roots. Annual $P$. edulis plants were treated at $4{ }^{\circ} \mathrm{C}$ for $72 \mathrm{~h}$ (cold treatment) and then treated at $25{ }^{\circ} \mathrm{C}$ for $72 \mathrm{~h}$ (recovery treatment). The stress-treated samples (leaves) included samples collected at $1 \mathrm{~h}, 4 \mathrm{~h}$, $8 \mathrm{~h}, 24 \mathrm{~h}$ and $72 \mathrm{~h}$ during cold treatment and recovery treatment, with one control sample. Each sample had three biological replicates. A total of 60 samples were stored at $-80^{\circ} \mathrm{C}$.

\section{RNA Isolation and cDNA Synthesis}

Total RNA was isolated from 60 samples by using the RNAprep Pure Plant Kit (Tiangen, Beijing, China) according to the steps in the manufacturer's protocol. Two percent $(\mathrm{w} / \mathrm{v})$ agarose gel electrophoresis was performed to validate the RNA quality, and a NanoDrop $2000 \mathrm{c}$ spectrophotometer (Thermo Scientific, Wilmington, USA) was used to determine the RNA concentration. Then $1 \mu \mathrm{g}$ of total RNA was used to

synthesize cDNA by applying the PrimeScript ${ }^{\mathrm{TM}} \mathrm{RT}$ Master Mix system (TaKaRa, Dalian, China), following the steps described in the manufacturer's instructions.

\section{Primer Design for Candidate Reference Genes}

According to previous studies, we selected 10 candidate reference genes: 50S, Ts, OTU, OmpH, Liom, EF1, UBQ, 18S, eIF5A, and HIS. Oligo 7 software (https://en.freedownloadmanager.org/Windows-

PC/OLIGO.html) was used to design primers for RT-qPCR with the following parameterS: the lengths of primers were $17-25 \mathrm{bp}$, the GC content of the primers was $40-60 \%$, the melting temperature was $58-62$ ${ }^{\circ} \mathrm{C}$, and the lengths of the products were $80-210$ bp (Table 1). The mean amplification efficiency of the primers was calculated with LinRegPCR 2014.x software [34]. 


\section{Expression Levels of Candidate Reference Genes Detected by RT-qPCR}

RT-qPCR was performed on an ABI ViiA 7 platform (Applied Biosystems, Foster City, USA). Each reaction had a final volume of $10 \mu \mathrm{L}$, which included $1 \mu \mathrm{L}$ of cDNA, $5 \mu \mathrm{L}$ of $2 \times$ PowerUp $^{\text {TM }}$ SYBR $^{\text {TM }}$ Green Master Mix (TaKaRa, Dalian, China), $0.5 \mu \mathrm{L}$ of forward primer $(10 \mu \mathrm{M})$ and reverse primer $(10 \mu \mathrm{M})$ and $3 \mu \mathrm{L}$ of $\mathrm{ddH}_{2} \mathrm{O}$. The amplification was performed under the following standard thermal profile: $95^{\circ} \mathrm{C}$ for $20 \mathrm{~s}$ and 40 cycles of $95^{\circ} \mathrm{C}$ for $1 \mathrm{~s}$ and $60^{\circ} \mathrm{C}$ for $20 \mathrm{~s}$, followed by a melt curve step at $95^{\circ} \mathrm{C}$ for $15 \mathrm{~s}, 60{ }^{\circ} \mathrm{C}$ for $1 \mathrm{~min}$, and $95^{\circ} \mathrm{C}$ for $15 \mathrm{~s}$. All the reactions had three technical replicates.

\section{Data Analysis}

Three tools, namely, BestKeeper, NormFinder and geNorm were used to evaluate gene expression stability based on the RT-qPCR results [20-22]. The formula $E^{-\Delta C t}(\Delta C t=$ each $C t$ value - minimum $C t$ value, where $\mathrm{E}$ represents mean efficiency of primer) was used to transform Ct values to relative expression quantities, which were needed for geNorm and NormFinder analyses. However, the $\mathrm{Ct}$ values were directly imported into BestKeeper. The geNorm tool uses the average expression stability value (M) to select internal control genes. Candidate reference genes have a relatively small $M$ value, which indicates that these genes have relatively high expression stabilities [20]. At the same time, the pairwise variation $\left(V_{n / n+1}\right)$ value given by geNorm is useful for determining the minimum number of internal control genes [20]. By combining intergroup and intragroup variations in gene expression levels, NormFinder evaluates genes based on stability values [21]. A low stability value indicates high expression stability. In the BestKeeper algorithm, the coefficient of determination $\left(r^{2}, r\right.$ represents the Pearson correlation coefficient) and the SD are used to select reference genes [22].

\section{Verification of Reference Genes}

To test the reference genes TS and EF1, we chose ICE1 as a target gene and investigated the expression pattern of the ICE 1 gene in the leaves of $P$. edulis under cold stress. The leaves were collected from $P$. edulis treated with cold stress $\left(4^{\circ} \mathrm{C}\right)$ for $0 \mathrm{~h}(\mathrm{CK}), 1 \mathrm{~h}, 4 \mathrm{~h}, 8 \mathrm{~h}, 24 \mathrm{~h}$, and $72 \mathrm{~h}$. The primers for ICE for RTqPCR were 5'-AAGCCACAGACAACAAGGCA-3' (forward) and 5'-AGCACTGCGGACATTCTTCA-3' (reverse). All further steps are described above.

\section{Abbreviations}

RT-qPCR, reverse transcription quantitative polymerase chain reaction; 50S, 50S ribosomal protein; Ts, threonine synthase; UBQ, ubiquitin 1; OTU, OTU domain-containing protein; 18S, 18 S ribosomal RNA; $\mathrm{OmpH}$, outer membrane protein; EF1, elongation factor 1 alpha; elF5A eukaryotic translation initiation factor 5A; HIS, histone H3; Liom, Theobroma cacao L-isoaspartate 0-methyltransferase mRNA; ICE1, inducer of $\mathrm{CBF}$ expression; $\mathrm{CBF}, \mathrm{C}$-repeat-binding factor. 


\section{Declarations}

Ethics approval and consent to participate: Not applicable.

Consent to publish: Not applicable.

Availability of data and materials: The raw CT values for analysis can be found in the Supplementary Material 1.

Competing interests: The authors declare that they have no competing interests.

Funding: This study was financially funded by the following programs: the National Natural Science Foundation of China (Gran no. 31960576; for collecting materials and conducting experiment), the Priority Academic Program Development of Jiangsu Higher Education Institutions (PAPD; for manuscript preparation) and the Collaborative Innovation Plan of Jiangsu Higher Education (CIP; for data analysis and interpretation).

Authors' Contributions: Z.T. and H.F. contributed equally to this work. Experimental design: M.X., H.F. and Z.T. Collected plant materials and performed the experiments: H.F., A.L., N.R. and K.D. Data analysis: Z.T. and H.F. Manuscript writing: Z.T. and M.X. All authors approved the final draft.

Acknowledgments: We wish to thank our colleagues in the laboratory, namely, Haoran Qi, Tengfei Shen, Ling Wu, Heng Cai, Hao Rong, and Xin Han, for their contributions to conducting the experiments and writing the article.

\section{References}

1. Xu M, Li A, Teng Y, Sun Z, Xu M. Exploring the adaptive mechanism of Passiflora edulis in karst areas via an integrative analysis of nutrient elements and transcriptional profiles. BMC Plant Biol. 2019;19(1):185-200.

2. Liu S, Li A, Chen C, Cai G, Zhang L, Guo C, Xu M. De Novo Transcriptome Sequencing in Passiflora edulis Sims to Identify Genes and Signaling Pathways Involved in Cold Tolerance. Forests. 2017;8:435-48.

3. Dos Reis LCR, Facco EMP, Salvador M, Flores SH, de Oliveira Rios A. Antioxidant potential and physicochemical characterization of yellow, purple and orange passion fruit. J Food Sci Technol. 2018;55(7):2679-91.

4. Rosado RDS, Rosado LDS, Borges LL, Bruckner CH, Cruz CD, dos Santos CEM. Genetic Diversity of Sour Passion Fruit Revealed by Predicted Genetic Values. Agron J 2018, 111(1).

5. Mattar GS, Moraes CCd, Meletti LMM, Purquerio LFV. Accumulation and exportation of nutrients by yellow Passion fruit cv. IAC 275. Rev Bras Frutic 2018, 40(3).

6. Oliveira DA, Angonese M, Ferreira SRS, Gomes CL. Nanoencapsulation of passion fruit by-products extracts for enhanced antimicrobial activity. Food Bioprod Process. 2017;104:137-46. 
7. Dheda K, Huggett JF, Chang JS, Kim LU, Bustin SA, Johnson MA, Rook GA, Zumla A. The implications of using an inappropriate reference gene for real-time reverse transcription PCR data normalization. Anal Biochem. 2005;344:141-3.

8. Moreira VS, Soares VLF, Silva RJS, Sousa AO, Otoni WC, Costa MGC. Selection and validation of reference genes for quantitative gene expression analyses in various tissues and seeds at different developmental stages in Bixa orellana L. Physiol Mol Biol Plants. 2018;24(3):369-78.

9. Lee PD, Sladek R, Greenwood CMT, Hudson TJ. Control Genes and Variability: Absence of Ubiquitous Reference Transcripts in Diverse Mammalian Expression Studies. Genome Res. 2002;12:292-7.

10. Hong S-Y, Seo PJ, Yang M-S, Xiang F, Park C-M. Exploring valid reference genes for gene expression studies in Brachypodium distachyon by real-time PCR. BMC Plant Biol. 2008;8:112-22.

11. Bao W, Qu Y, Shan X, Wan Y. Screening and Validation of Housekeeping Genes of the Root and Cotyledon of Cunninghamia lanceolata under Abiotic Stresses by Using Quantitative Real-Time PCR. Int J Mol Sci. 2016;17(8):1198-214.

12. Liu YK, Li HP, Huang T, Cheng W, Gao CS, Zuo DY, Zhao ZX, Liao YC. Wheat-specific gene, ribosomal protein 121 , used as the endogenous reference gene for qualitative and real-time quantitative polymerase chain reaction detection of transgenes. J Agric Food Chem. 2014;62(43):10405-13.

13. Die JV, Roman B, Nadal S, Gonzalez-Verdejo Cl. Evaluation of candidate reference genes for expression studies in Pisum sativum under different experimental conditions. Planta. 2010;232:14553.

14. Bustin SA. Quantification of mRNA using real-time reverse transcription PCR (RT-PCR): trends and problems. J Mol Endocrinol. 2002;29:23-9.

15. Gutierrez L, Mauriat M, Guenin S, Pelloux J, Lefebvre JF, Louvet R, Rusterucci C, Moritz T, Guerineau F, Bellini $\mathrm{C}$, et al. The lack of a systematic validation of reference genes: a serious pitfall undervalued in reverse transcription-polymerase chain reaction (RT-PCR) analysis in plants. Plant Biotechnol J. 2008;6:609-18.

16. Mehennaoui K, Legay S, Serchi T, Guerold F, Giamberini L, Gutleb AC, Cambier S. Identification of reference genes for RT-qPCR data normalization in Gammarus fossarum (Crustacea Amphipoda). Sci Rep. 2018;8(1):15225-32.

17. Huggett J, Dheda K, Bustin S, Zumla A. Real-time RT-PCR normalisation; strategies and considerations. Genes Immun. 2005;6(4):279-84.

18. Zhu P, Ma Y, Zhu L, Chen Y, Li R, Kongshu J. Selection of Suitable Reference Genes in Pinus massoniana Lamb. Under Different Abiotic Stresses for qPCR Normalization. Forests 2019, 10(8).

19. Tu Z, Hao Z, Zhong W, Li H. Identification of Suitable Reference Genes for RT-qPCR Assays in Liriodendron chinense (Hemsl.) Sarg. Forests 2019, 10(5).

20. Vandesompele J, Preter KD, Pattyn F, Poppe B, Roy NV, paepe AD, Speleman F. Accurate normalization of real-time quantitative RT-PCR data by geometric averaging of multiple internal.pdf. Genome Biol. 2002;3(7):0034.0031-0034.0011. 
21. Andersen CL, Jensen JL, Orntoft TF. Normalization of real-time quantitative reverse transcription-PCR data: a model-based variance estimation approach to identify genes suited for normalization, applied to bladder and colon cancer data sets. Cancer Res. 2004;64(15):5245-50.

22. Pfaffl MW, Tichopad A, Prgomet C, Neuvians TP. Determination of stable housekeeping genes, differentially regulated target genes and sample integrity: BestKeeper - Excel-based tool using pairwise correlations. Biotechnol Lett. 2004;26:509-15.

23. Vera Hernandez FP, Martinez Nunez M, Ruiz Rivas M, Vazquez Portillo RE, Bibbins Martinez MD, Luna Suarez S, Rosas Cardenas FF. Reference genes for RT-qPCR normalisation in different tissues, developmental stages and stress conditions of amaranth. Plant Biol (Stuttg). 2018;20(4):713-21.

24. Nguyen DQ, Eamens AL, Grof CPL. Reference gene identification for reliable normalisation of quantitative RT-PCR data in Setaria viridis. Plant methods. 2018;14:24-35.

25. Zhang K, Li M, Cao S, Sun Y, Long R, Kang J, Yan L, Cui H. Selection and validation of reference genes for target gene analysis with quantitative real-time PCR in the leaves and roots of Carex rigescens under abiotic stress. Ecotoxicol Environ Saf. 2018;168:127-37.

26. Liu Q, Qi X, Yan H, Huang L, Nie G, Zhang X. Reference Gene Selection for Quantitative Real-Time Reverse-Transcriptase PCR in Annual Ryegrass (Lolium multiflorum) Subjected to Various Abiotic Stresses. Molecules. 2018;23(1):172-88.

27. Liang W, Zou X, Carballar-Lejarazu R, Wu L, Sun W, Yuan X, Wu S, Li P, Ding H, Ni L, et al. Selection and evaluation of reference genes for qRT-PCR analysis in Euscaphis konishii Hayata based on transcriptome data. Plant methods. 2018;14:42-50.

28. Zhao N, Yan Y, Wang H, Bai S, Wang Q, Liu W, Wang J. Acetolactate Synthase Overexpression in Mesosulfuron-Methyl-Resistant Shortawn Foxtail (Alopecurus aequalis Sobol.): Reference Gene Selection and Herbicide Target Gene Expression Analysis. J Agric Food Chem. 2018;66(37):9624-34.

29. Wei J, Li F, Guo J, Li X, Xu J, Wu G, Zhang D, Yang L. Collaborative Ring Trial of the Papaya Endogenous Reference Gene and Its Polymerase Chain Reaction Assays for Genetically Modified Organism Analysis. J Agric Food Chem. 2013;61:11363-70.

30. Nonis A, Vezzaro A, Ruperti B. Evaluation of RNA extraction methods and identification of putative reference genes for real-time quantitative polymerase chain reaction expression studies on olive (Olea europaea L.) fruits. J Agric Food Chem. 2012;60(27):6855-65.

31. Obrero A, Die JV, Roman B, Gomez P, Nadal S, Gonzalez-Verdejo Cl. Selection of reference genes for gene expression studies in zucchini (Cucurbita pepo) using qPCR. J Agric Food Chem. 2011;59(10):5402-11.

32. Wu G, Zhang L, Wu Y, Cao Y, Lu C. Comparison of five endogenous reference genes for specific PCR detection and quantification of Brassica napus. J Agric Food Chem. 2010;58(5):2812-7.

33. Xu M, Zhang B, Su X, Zhang S, Huang M. Reference gene selection for quantitative real-time polymerase chain reaction in Populus. Anal Biochem. 2011;408(2):337-9.

34. Ruijter JM, Ramakers C, Hoogaars WMH, Karlen Y, Bakker O, Hoff MJBvd, Moorman AFM. Amplification efficiency: linking baseline and bias in the analysis of quantitative PCR data. Nucleic 
Acids Res. 2009;37(6):e45.

35. Jain N, Vergish S, Khurana JP. Validation of house-keeping genes for normalization of gene expression data during diurnal/circadian studies in rice by RT-qPCR. Scientific reports. 2018;8:3203.

36. Wu J, Zhang H, Liu L, Li W, Wei Y, Shi S. Validation of Reference Genes for RT-qPCR Studies of Gene Expression in Preharvest and Postharvest Longan Fruits under Different Experimental Conditions. Frontiers in plant science. 2016;7:780.

37. Xiang D, Chai Y, Man L, Sun Y, Zhang T, Wei C, Xie Z, Li H, Zhang W, Liu D, et al. Overexpression of a heading Chinese cabbage ICE1 gene confers freezing tolerance in transgenic rice. Plant Cell Tissue Organ Cult. 2016;128(1):43-54.

38. Wu J, Zhang J, Pan Y, Huang H, Lou X, Tong Z. Identification and evaluation of reference genes for normalization in quantitative real-time PCR analysis in the premodel tree Betula luminifera. J For Res. 2016;28(2):273-82.

39. Wan D, Wan Y, Yang Q, Zou B, Ren W, Ding Y, Wang Z, Wang R, Wang K, Hou X. Selection of Reference Genes for qRT-PCR Analysis of Gene Expression in Stipa grandis during Environmental Stresses. PloS one. 2017;12(1):e0169465.

40. Jacob F, Guertler R, Naim S, Nixdorf S, Heinzelmann-Schwarz V. Careful Selection of Reference Genes Is Required for Reliable Performance of RT-qPCR in Human Normal and Cancer Cell Lines. PloS one. 2013;8(3):1-8.

41. Avraham T, Amir R. The expression level of threonine synthase and cystathionine-y-synthase is influenced by the level of both threonine and methionine in Arabidopsis plants. Transgenic Res. 2005;14(3):299-311.

42. Garrido-Franco M, Ehlert S, Messerschmidt A, Marinkovic S, Huber R, Laber B, Bourenkov GP, Clausen T. Structure and function of threonine synthase from yeast. J Biol Chem. 2002;277(14):12396-405.

43. Acevedo RM, Avico EH, Ruiz OA, Sansberro PA. Assessment of reference genes for real-time quantitative PCR normalization in Ilex paraguariensis leaves during drought. Biol Plant. 2018;62(1):89-96.

44. Tang X, Zhang N, Si H, Calderon-Urrea A. Selection and validation of reference genes for RT-qPCR analysis in potato under abiotic stress. Plant methods. 2017;13:85-92.

45. Wang ML, Li QH, Xin HH, Chen X, Zhu XJ, Li XH. Reliable reference genes for normalization of gene expression data in tea plants (Camellia sinensis) exposed to metal stresses. PloS one. 2017;12(4):e0175863.

46. Wu ZJ, Tian C, Jiang Q, Li XH, Zhuang J. Selection of suitable reference genes for qRT-PCR normalization during leaf development and hormonal stimuli in tea plant (Camellia sinensis). Scientific reports. 2016;6:19748.

47. Schmidt GW, Delaney SK. Stable internal reference genes for normalization of real-time RT-PCR in tobacco (Nicotiana tabacum) during development and abiotic stress. Molecular genetics genomics: MGG. 2010;283(3):233-41. 
48. Wang Y, Chen Y, Ding L, Zhang J, Wei J, Wang H. Validation of Reference Genes for Gene Expression by Quantitative Real-Time RT-PCR in Stem Segments Spanning Primary to Secondary Growth in Populus tomentosa. PloS one. 2016;11(6):e0157370.

49. Zhou L, Chen F, Ye J, Pan H. Selection of Reliable Reference Genes for RT-qPCR Analysis of Bursaphelenchus mucronatus Gene Expression From Different Habitats and Developmental Stages. Front Genet. 2018;9:269-79.

50. Sgamma T, Pape J, Massiah A, Jackson S. Selection of reference genes for diurnal and developmental time-course real-time PCR expression analyses in lettuce. Plant methods. 2016;12:21-9.

51. Liu X, Guan H, Song M, Fu Y, Han X, Lei M, Ren J, Guo B, He W, Wei Y. Reference gene selection for qRT-PCR assays in Stellera chamaejasme subjected to abiotic stresses and hormone treatments based on transcriptome datasets. PeerJ 2018:4535-4555.

52. Wang DZ, Jin YN, Ding XH, Wang WJ, Zhai SS, Bai LP, Guo ZF. Gene Regulation and Signal Transduction in the ICE-CBF-COR Signaling Pathway during Cold Stress in Plants. Biochemistry. 2017;82(10):1103-17.

\section{Figures}



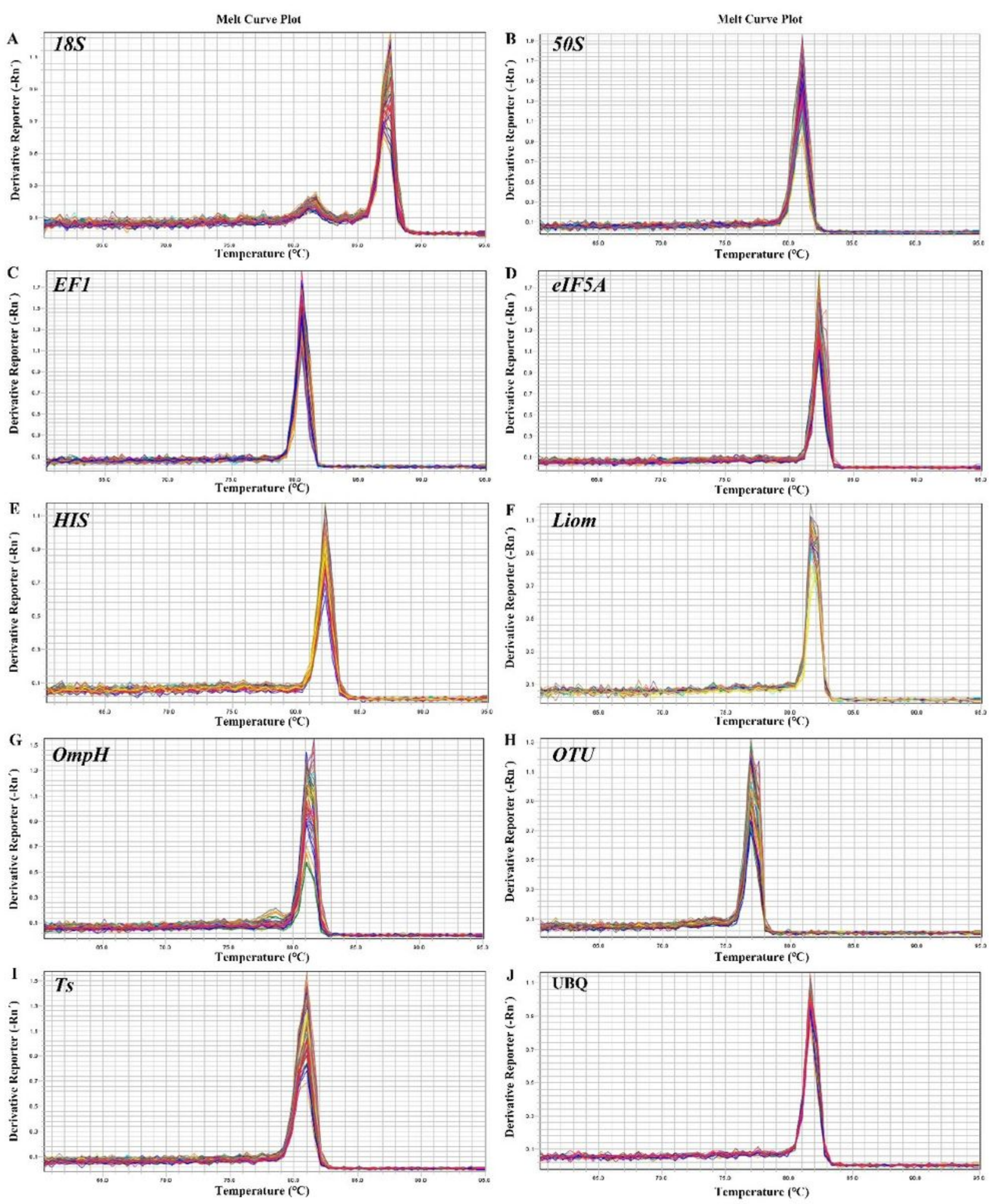

Figure 1

Melt curve plots of ten candidate reference genes. (a) - (j) Melt curve plots of 18S, 50S, EF1, elF5A, HIS, Liom, OmpH, OTU, Ts, and UBQ. 


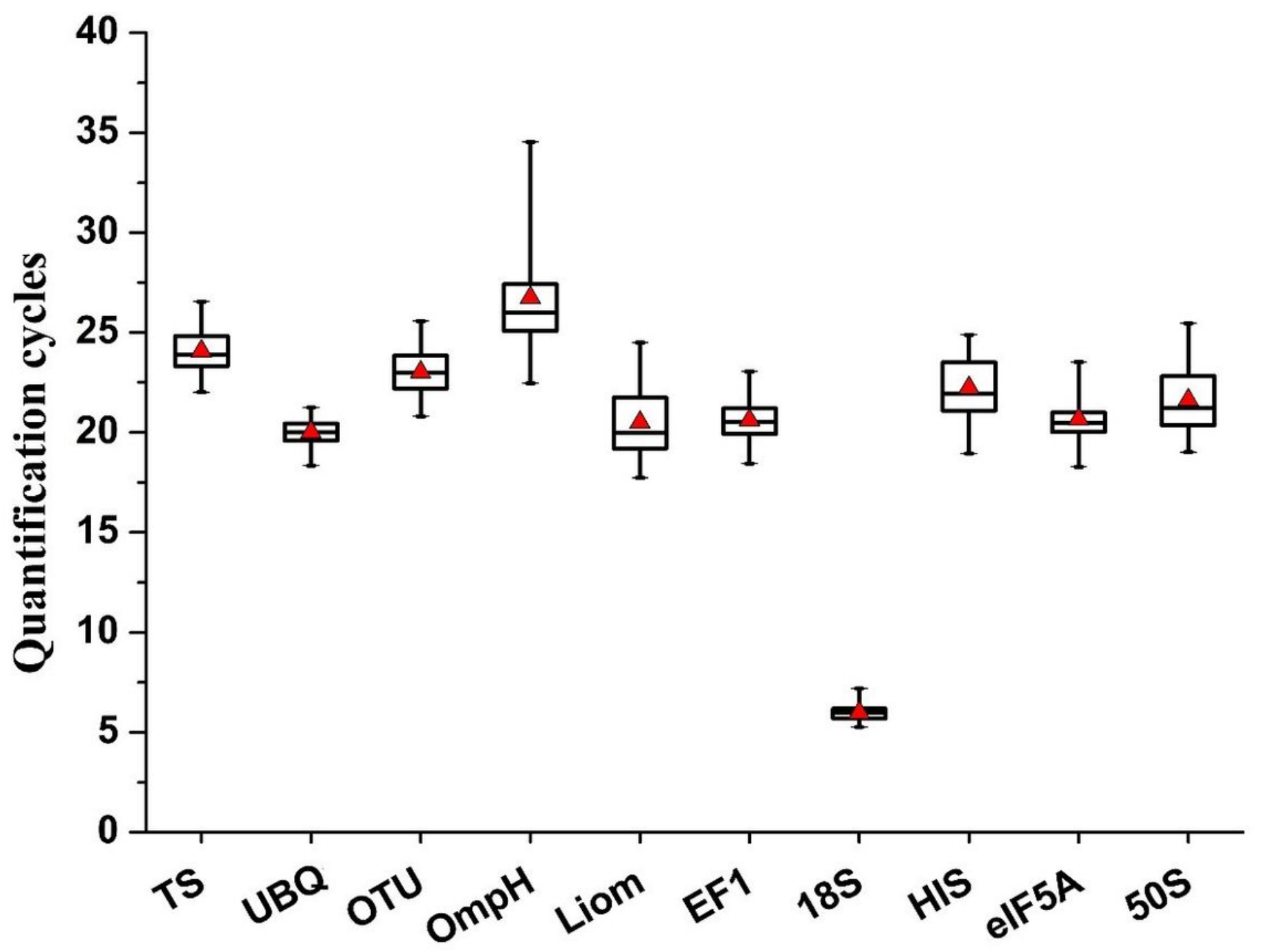

Figure 2

Box map of $\mathrm{Ct}$ values for the 10 candidate internal control genes. The 25th, 50th and 75 th percentiles are indicated by boxes. Red triangles represent the mean $\mathrm{Ct}$ values of the candidate reference genes. The maximum and minimum $\mathrm{Ct}$ values are indicated by whiskers. 

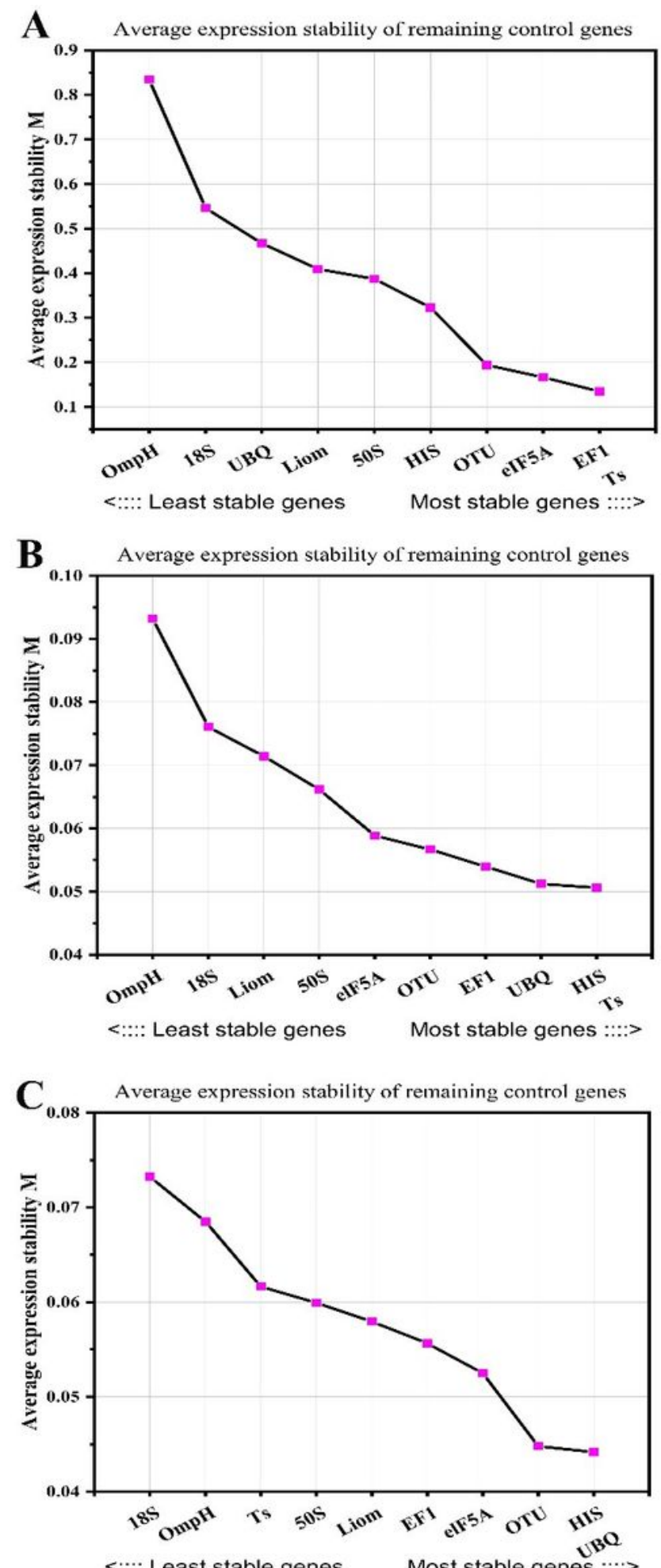

\section{Figure 3}

Ranking of the gene expression stability calculated by geNorm. Ranking of the gene expression stability in all samples (a), tissue samples (b), and cold-treated samples (c). A low average expression stability value, $M$, indicates high expression stability. 


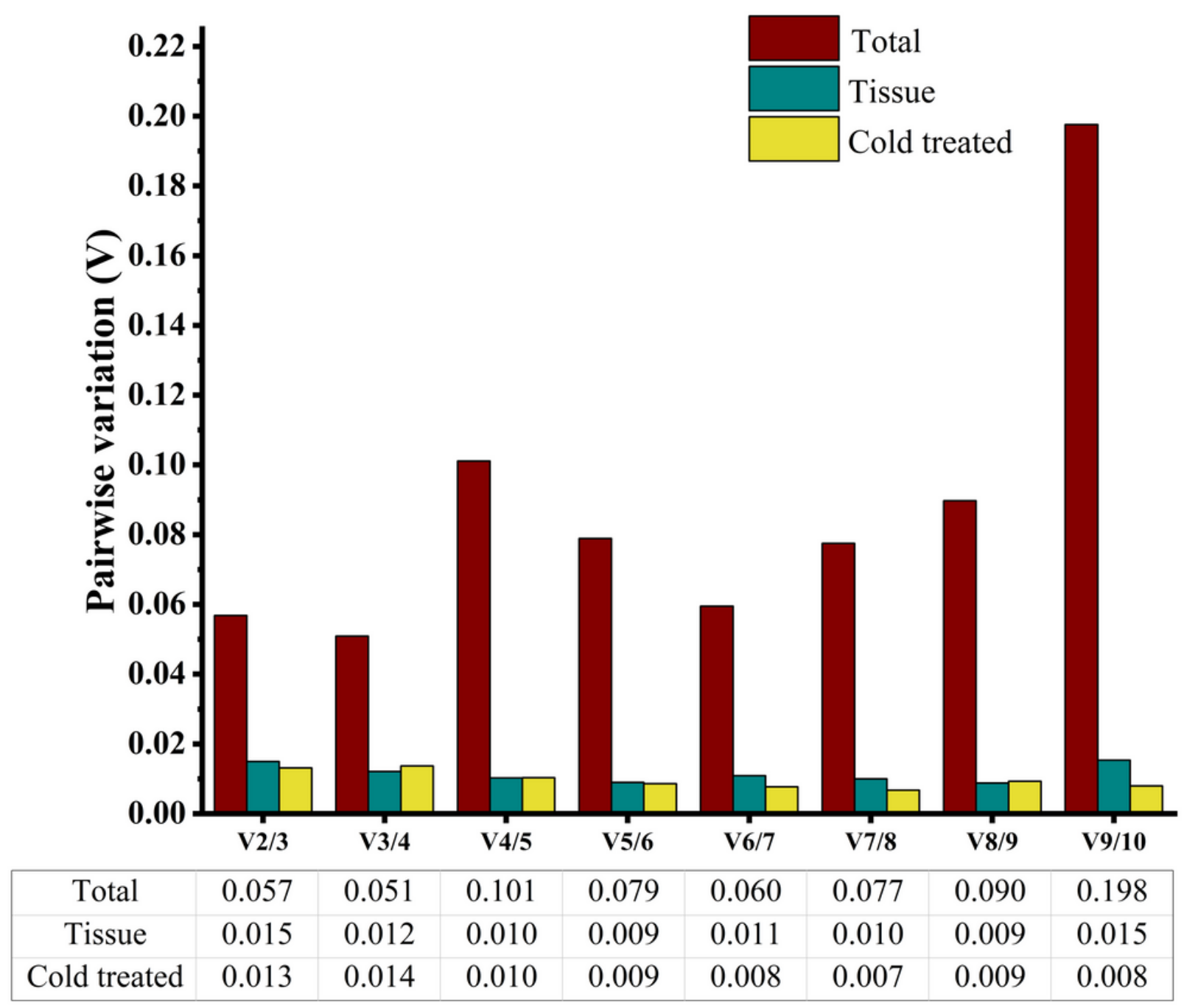

Figure 4

Pairwise variation $(\mathrm{V})$ of ten candidate reference genes calculated by geNorm. If $\mathrm{Vn} / \mathrm{n}+1$ values exceed 0.15 , an additional internal control gene must be included for normalization. In total samples, tissue samples, and cold-treated samples, V2/3 values were less than 0.15 , indicating that two reference genes were sufficient for RT-qPCR data normalization. 

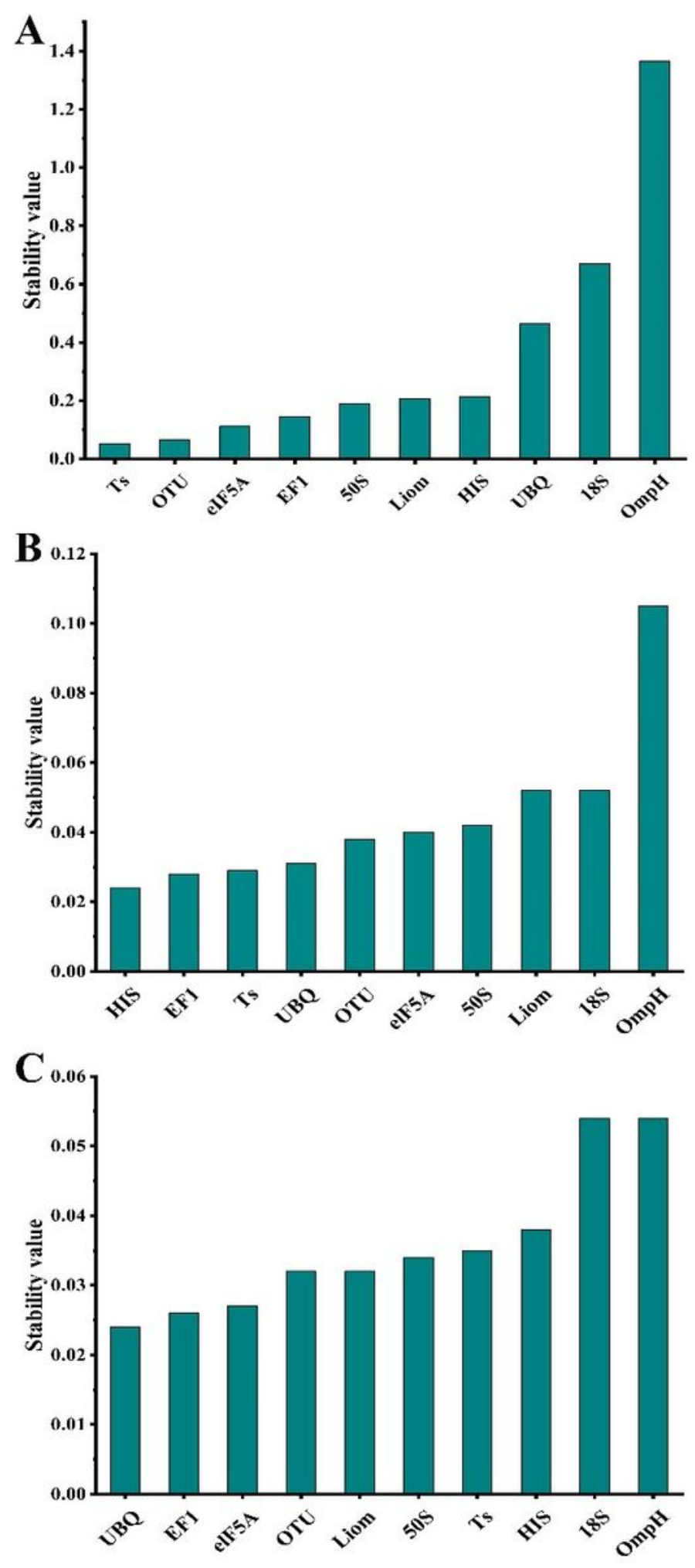

Figure 5

Ranking of the gene expression stability calculated by NormFinder. A low stability value indicates increased expression pattern stability. Ranking of the expression stability of genes in all samples (a), tissue samples (b), and cold stress-treated samples (c). 


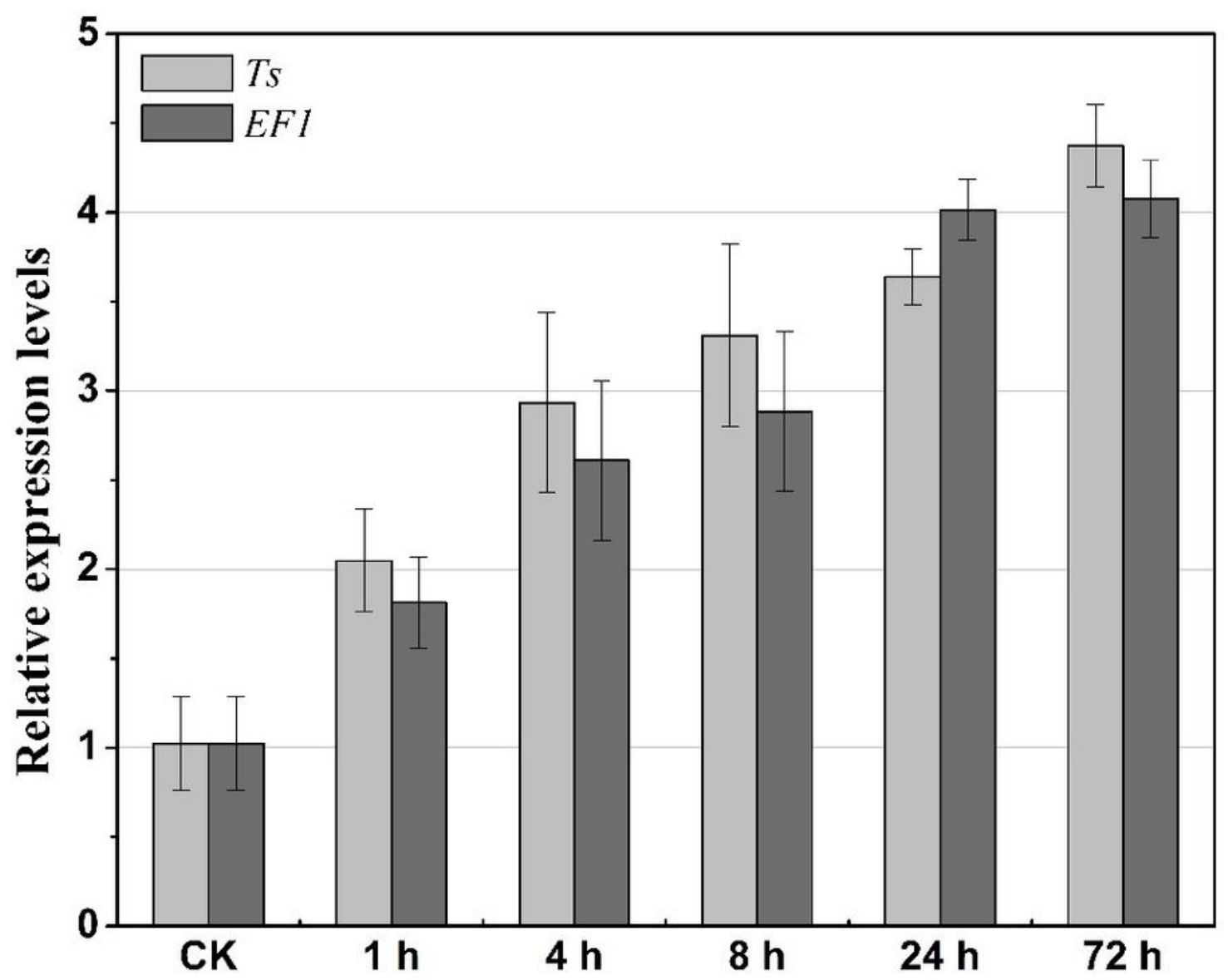

Figure 6

Investigation of the expression levels of ICE1 under cold stress in P. edulis. P. edulis was treated at $4{ }^{\circ} \mathrm{C}$ for $0 \mathrm{~h}$ (CK), $1 \mathrm{~h}, 4 \mathrm{~h}, 8 \mathrm{~h}, 24 \mathrm{~h}$, and $72 \mathrm{~h}$.

\section{Supplementary Files}

This is a list of supplementary files associated with this preprint. Click to download.

- SupplementaryMaterial1.xlsx 